\title{
Article
}

\section{The Effectiveness of Computer-Assisted Cognitive Rehabilitation and the Degree of Recovery in Patients with Traumatic Brain Injury and Stroke}

\author{
Hyunwoo Jung ${ }^{1,+}$, Jae-Gyeong Jeong ${ }^{1,+} \oplus$, Youn-Soo Cheong ${ }^{1}$, Tae-Woo Nam ${ }^{1}$, Ju-Hyun Kim ${ }^{1}$, \\ Chan-Hee Park ${ }^{1} \mathbb{1}$, Eunhee Park ${ }^{2,3, * \mathbb{C}}$ and Tae-Du Jung $2,3, * \mathbb{C}$ \\ 1 Department of Rehabilitation Medicine, Kyungpook National University Hospital, Daegu 41944, Korea; \\ hwjung_87@naver.com (H.J.); cloud90524@naver.com (J.-G.J.); yscheong@gmail.com (Y.-S.C.); \\ n0530@daum.net (T.-W.N.); kjoohyun88@gmail.com (J.-H.K.); chany9090@gmail.com (C.-H.P.) \\ 2 Department of Rehabilitation Medicine, Kyungpook National University Chilgok Hospital, \\ Daegu 41404, Korea \\ 3 Department of Rehabilitation Medicine, School of Medicine, Kyungpook National University, \\ Daegu 41944, Korea \\ * Correspondence: ehmdpark@naver.com (E.P.); teeed0522@hanmail.net (T.-D.J.) \\ + Contributed equally to this work as first author.
}

check for

updates

Citation: Jung, H.; Jeong, J.-G.; Cheong, Y.-S.; Nam, T.-W.; Kim, J.-H.; Park, C.-H.; Park, E.; Jung, T.-D. The Effectiveness of Computer-Assisted Cognitive Rehabilitation and the Degree of Recovery in Patients with Traumatic Brain Injury and Stroke. J. Clin. Med. 2021, 10, 5728. https:// doi.org/10.3390/jcm10245728

Academic Editor: Ana Maria Bugă

Received: 18 October 2021

Accepted: 2 December 2021

Published: 7 December 2021

Publisher's Note: MDPI stays neutral with regard to jurisdictional claims in published maps and institutional affiliations.

Copyright: (C) 2021 by the authors Licensee MDPI, Basel, Switzerland. This article is an open access article distributed under the terms and conditions of the Creative Commons Attribution (CC BY) license (https:/ / creativecommons.org/licenses/by/ $4.0 /)$.
Abstract: Objectives: To determine the effectiveness of computer-assisted cognitive rehabilitation and compare the patterns of cognitive function recovery occurring in both traumatic brain injury (TBI) and stroke. Methods: A total of 62 patients were finally enrolled, consisting of 30 with TBI and 32 with stroke. The patients received 30 sessions of computer-assisted cognitive rehabilitation (Comcog) five times per week. Each session lasted for $30 \mathrm{~min}$. Before and immediately after cognitive rehabilitation, all patients were evaluated by computerized neuropsychological test (CNT), MiniMental State Examination (MMSE), and modified Barthel index (MBI). Results: We analyzed the differences between pre- and post-cognitive rehabilitation in each TBI and stroke group. Significant differences were observed in MMSE, MBI, and some CNT contents, including digit span forward, verbal learning, verbal learning delayed recall, visual span forward, visual span backward, visual learning, trail making test A and B, and intelligence quotient (IQ) in the TBI group $(p<0.05)$. In the stroke group, in addition to significant differences that appeared in the TBI group, additional significant differences in the digit span backward, visual learning delayed recall, auditory continuous performance test (CPT), visual CPT, and card sorting test. We compared the difference values at pre- and post-cognitive rehabilitation for cognitive recovery between the TBI and stroke groups. All contents, except the digital span forward, visual learning, word-color test, and MMSE, had greater mean values in the stroke group; and thus, statistically significant higher values were observed in the visual span forward and card sorting test $(p<0.05)$. Conclusion: Most evaluation results showed improvement and the evaluation between the TBI and stroke groups also showed significant differences in cognitive functions in addition to more CNT contents, which significantly change in the stroke group. The stroke group showed a high difference value in most CNT contents. Therefore, those with stroke in the focal brain region tend to have better cognitive function recovery after a computer-assisted cognitive rehabilitation than those with TBI, which could cause diffuse brain damage and post-injury inflammation.

Keywords: traumatic brain injury; stroke; computer-assisted cognitive rehabilitation; computerized neuropsychological test

\section{Introduction}

Acquired brain injury, including traumatic brain injury (TBI) and stroke, causes several neurological deficits, resulting in serious problems for the patients and public 
health [1,2]. The complications for each individual vary and depend on the site of lesion and severity of the injury. Among other complications, the impaired cognitive function becomes an obstacle that devestates both patients and caregivers and is not only an obstacle to the rehabilitation program [3], it exerts a detrimental effect on the degree of functional status and disability [4]. Therefore, cognitive rehabilitation is necessary for the effective management of acquired brain injuries.

Cognitive rehabilitation was started for patients with brain injuries during World War I for improved survival [5]. Since then, researchers have developed various cognitive rehabilitation techniques and models [6]. In general, two main categories have been established in cognitive rehabilitation techniques, conventional (paper/pencil exercises) and computerized rehabilitation. Both cognitive rehabilitation techniques retrain the patient's attention and concentration, visual processing, language, memory, reasoning and problem solving, and executive function deficits [7-10]. Conventional methods are manual exercises with the therapist, whereas computerized rehabilitation uses game-like programs, multimedia and informatics resources with specific hardware and software systems [11-15]. Computer-assisted rehabilitation is an increasingly effective method for patients with acquired brain injury. A recent systematic review shows evidence for computer-assisted rehabilitation in processing and memory ability [16]. Another study showed that computerassisted rehabilitation is more effective than conventional rehabilitation in digit and visual span, visual learning, and auditory and visual continuous performance [17].

Some commonalities are observed between the TBI and stroke. Since TBI and stroke differ in etiology as well as incidence age and incidence site, a difference in the degree/characteristic/modal/recovery of cognitive impairment is inevitable [18]. First, TBI is characterized by hemorrhagic cerebral contusions originating from acceleration/deceleration with or without striking the head to an object [19]. Diffuse axonal injury with hemorrhagic contusion affects all brain areas in addition to noticeable hemorrhage [20]. The spectrum of cognitive deficits following TBI includes attentional dysfunction, anterograde memory disturbance, language abnormalities, visuospatial deficits, and executive dysfunction [21]. Post-stroke cognitive impairment in both ischemic and hemorrhagic stroke commonly occurs but with diverse clinical manifestations [22]. Deficits are present in various cognitive domains, such as executive function, memory, visuospatial ability, and/or language [23]. However, unlike TBI, instead of receiving injury over the entire brain area, relatively limited problems related to the lesion location increase.

As described above, the pattern and degree of cognitive impairment recovery in patients with stroke and TBI may differ [24]. For this, several studies have been conducted on the recovery of cognitive function in stroke and TBI, respectively [25-27]. However, a few studies have addressed the recovery pattern differences between the two diseases. Therefore, this study aimed to determine the effectiveness of computer-assisted rehabilitation and compare the patterns of cognitive function recovery occurring in both TBI and stroke. Thus, the cognitive dysfunction associated with stroke and TBI could be better understood and helpful in predicting the prognosis.

\section{Materials and Methods}

\subsection{Patients}

From December 2013 to October 2019, patients with stroke and TBI who were referred to the rehabilitation department of Chilgok Kyungpook National University Hospital were recruited. Inclusion criteria included (1) patients diagnosed with stroke or TBI using computed tomography and magnetic resonance imaging and (2) patients with impaired cognition (MMSE score of $\leq 27$ ).

Patients were excluded from the study in the following cases: (1) the presence of a previous central nervous system lesion such as TBI, stroke, brain tumor, and epilepsy; (2) an impossible one-step obey command due to higher brain dysfunction (aphasia or hemispatial neglect) or poor cooperation; (3) the presence of a visual or hearing impairment that interferes with cognitive rehabilitation; and (4) unstable vital signs. 
When we reviewed the charts, a total of 854 patients with TBI or stroke were recruited, excluding 757 who met the exclusion criteria in a retrospective study. Of the remaining 97 patients, 35 who did not complete a cognitive rehabilitation program or did not undergo follow-up evaluation and were excluded. As a result, 62 people were finally enrolled, consisting of 30 with TBI and 32 with stroke. The retrospective study was approved by the institutional review board of the hospital (IRB No. 2019-05-008).

\subsection{Computer-Assisted Cognitive Rehabilitation}

Participants underwent 30 sessions of computer-assisted cognitive rehabilitation (Com$\operatorname{cog}{ }^{\circledR}$, Version 1.0, Maxmedica, Seoul, Korea) [28] five times per week. Each session lasted for 30 min per time. The Comcog is a computer-assisted cognitive training system that has been used for years in South Korea [29]. The system provides 10 training activities: 2 auditory processing tasks that assess response time during auditory stimulation; 2 visual processing tasks that assess response time during visual stimulation; 2 selective attention tasks that track attention in distraction; 3 working memory tasks that assess recognition and recall memory using visual, auditory, and multisensory stimulation; and 1 emotional attention task that assesses responses to pleasant or unpleasant stimulation [29].

\subsection{Assessments}

Before starting the cognitive rehabilitation, all patients underwent a computerized neuropsychological test (CNT), a Mini-Mental Status Examination (MMSE), and a modified Barthel index (MBI) performed by occupational therapists. After 30 sessions of Comcog, we reevaluated CNT, MMSE and MBI to determine the cognitive function improvement.

The computerized neuropsychological test (CNT, Version 4.0, Maxmedica, Seoul, Korea) was used for the cognitive function test. The CNT is composed of five components: Verbal memory, visual memory, attention, visuomotor coordination, and high cognition test, which are all computerized as one program (Figure 1). There are tests for each component and the results were presented based on a percentage. Then, the T-score was calculated [30].

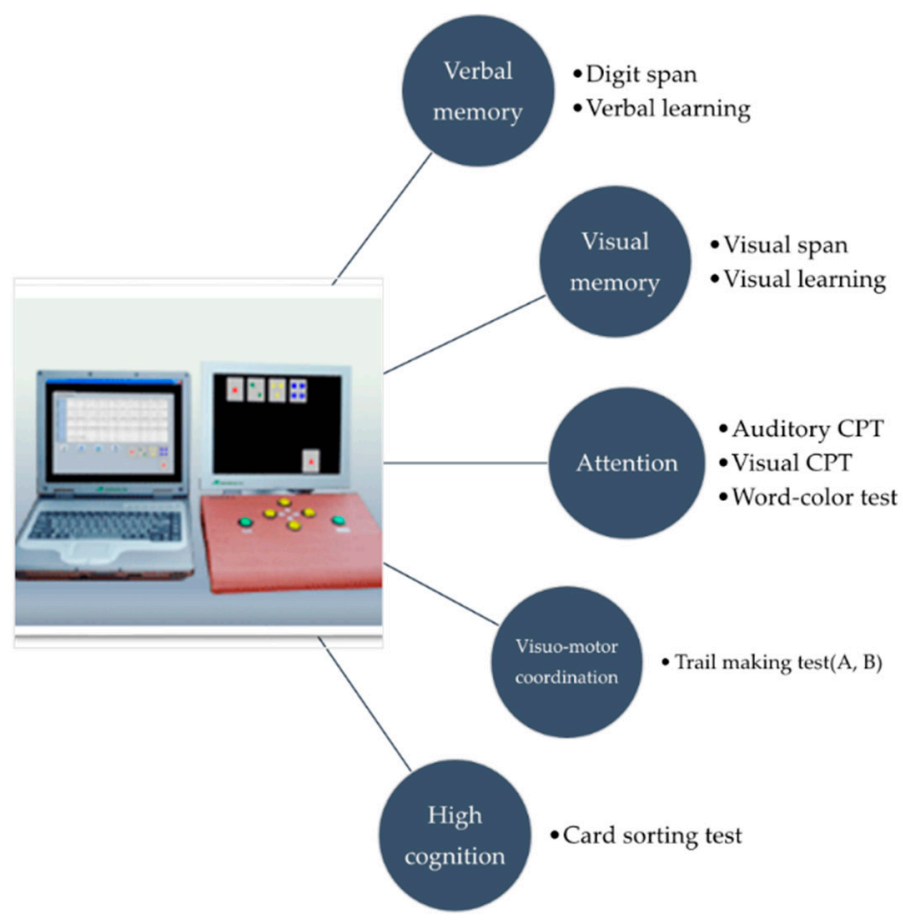

Figure 1. Computerized Neuropsychological Test. 


\subsubsection{Verbal Memory Test}

1. Digit span test: Digit span forward test follows the number played through the computer speaker as it is and a digit span backward test speaks in reverse.

2. Verbal learning test: A total of 15 target words are heard through the computer speaker, recalled in any order and the same target word is repeated five times. After listening to the target word five times, 15 new words are heard and then recalled for blocking and then the 15 target words are recalled again. After $20 \mathrm{~min}, 15$ target words are recalled again and a word list containing 30 words including the target words is presented on the screen and the target words are searched for the delayed recall test.

\subsubsection{Visual Memory Test}

1. Visual span test: When nine circles flash in sequence on the screen, a forward visual span test can memorize the order and be clicked with a mouse. A backward visual span test repeats it backward; therefore, the most memorized number is calculated as a score.

2. Visual learning test: After presenting 15 figures on the screen, the patient was instructed to remember the figures. Then, the previously presented figures among 30 figures with the added 15 figures that were not presented were added. After repeating five times in the same way, patients were asked to recall the 15 figures that were previously presented after $20 \mathrm{~min}$ for the delayed recall test.

\subsubsection{Attention Test}

1. Auditory continuous performance test (CPT): An auditory CPT allows the patient to press a button when the patient hears the number three while playing multiple numbers through the speaker. The response time is scored.

2. Visual CPT: A visual CPT allows the patient to press a button when the patient sees number 3 while showing multiple numbers through the monitor. The response time is scored.

3. Word-color test: It is a test that lists 24 letters of "green," "blue," "yellow," and "red" and the corresponding colors to read them as quickly as possible. Several tests consist of (A) reading black letters, (B) the test to read the color by presenting each color square, (C) the test to read letters that match the color of the letter, and (D) the test to read the color of the letter whose color that composes the letter does not match the letter. The response time is scored.

\subsubsection{Visuomotor Coordination Test}

1. Trail making test (TMT): TMT-A is a test that connects numbers up to 25 on the screen, respectively. TMT-B connects the numbers and letters alternately, respectively.

\subsubsection{High Cognition Test}

1. Card sorting test: It is a test in which the reference cards with different shapes, colors, and numbers are presented, a problem card and one of three standards are presented and a reference card corresponding to the same standard should be selected.

\subsection{Statistical Analyses}

Data were statistically analyzed using IBM SPSS version 23 (SPSS, Inc., Chicago, IL, USA). The student's t-test was used to determine significant differences in the CNT contents, MMSE, and MBI between the TBI and stroke groups. To confirm the significant differences in CNT contents, MMSE, and MBI at pre- and post-cognitive rehabilitation in each of the TBI and stroke groups, a paired t-test was used. A value of $p<0.05$ was considered statistically significant. 


\section{Results}

\subsection{Participant Characteristics}

A total of 62 patients (30 TBI and 32 stroke patients) participated in this study. Among stroke patients, 12 had right hemispheric lesion, 18 had left hemispheric lesion and 2 had bilateral lesion. Also, 14 had cerebral infarction and 18 had cerebral hemorrhage and all stroke patients had lesions in the supratentorial area. We investigated the age, sex, duration from disease onset to the initial CNT evaluation (post-onset duration), duration of cognitive rehabilitation by Comcog (cognitive rehabilitation duration), initial MMSE and initial MBI as the descriptive data. These data are summarized in Table 1.

Table 1. Descriptive statistics for TBI and stroke groups.

\begin{tabular}{cccc}
\hline Variables & TBI $(\boldsymbol{n = 3 0 )}$ & Stroke $(\boldsymbol{n = 3 2 )}$ & $p$-Value ${ }^{\dagger}$ \\
\hline Gender $(n)$ & & & 0.362 \\
Male & 22 & 20 & \\
Female & 8 & 12 & 0.772 \\
Age (years) & $59.03 \pm 17.22$ & $57.78 \pm 16.66$ & 0.205 \\
Post-onset duration (days) & $74.03 \pm 43.59$ & $61.13 \pm 35.46$ & 0.452 \\
Cognitive rehabilitation & $52.50 \pm 8.46$ & $51.06 \pm 6.39$ & \\
$\quad$ duration (days) & & & 0.055 \\
Initial behavioral parameter & $17.70 \pm 6.00$ & $20.44 \pm 4.99$ & 0.477 \\
MMSE & $47.00 \pm 27.91$ & $42.13 \pm 25.71$ & \\
MBI & &
\end{tabular}

Mean \pm Standard deviation; TBI, traumatic brain injury; post-onset duration, duration from disease onset to the initial CNT evaluation; cognitive rehabilitation duration, duration of cognitive rehabilitation by Comcog; MMSE, Mini-Mental State Examination; MBI, modified Barthel index; ${ }^{\dagger} p$-value, comparison between the TBI and stroke groups.

\subsection{Comparison of Evaluation Pre- and Post-Cognitive Rehabilitation by Comcog}

We analyzed the differences between pre- and post-cognitive rehabilitation in the TBI and stroke groups. Significant differences in MMSE, MBI, and some of CNT contents including digit span forward, verbal learning, verbal learning delayed recall, visual span forward, visual span backward, visual learning, TMT-A, TMT-B, and IQ were observed in the TBI group $(p<0.05)$. Moreover, significant differences were observed in MMSE, MBI and all contents of CNT, except for WCT in the stroke group (Table 2). In the stroke group, in addition to significant differences that also appeared in the TBI group, additional significant differences were observed in the digit span backward, visual learning delayed recall, auditory $\mathrm{CPT}$, visual $\mathrm{CPT}$, and card sorting test.

Table 2. Analyses of the differences between pre- and post-cognitive rehabilitation in the TBI and stroke groups.

\begin{tabular}{|c|c|c|c|c|c|c|}
\hline & \multicolumn{3}{|c|}{ TBI } & \multicolumn{3}{|c|}{ Stroke } \\
\hline & $\begin{array}{c}\text { Pre- } \\
\text { Rehabilitation }\end{array}$ & $\begin{array}{c}\text { Post- } \\
\text { Rehabilitation }\end{array}$ & $p$-Value ${ }^{\dagger}$ & $\begin{array}{c}\text { Pre- } \\
\text { Rehabilitation }\end{array}$ & $\begin{array}{c}\text { Post- } \\
\text { Rehabilitation }\end{array}$ & $p$-Value $\ddagger$ \\
\hline $\begin{array}{l}\text { Digital span } \\
\text { test_forward }\end{array}$ & $35.33 \pm 10.14$ & $40.06 \pm 13.98$ & 0.009 * & $34.03 \pm 9.37$ & $38.03 \pm 10.11$ & $0.023 *$ \\
\hline $\begin{array}{l}\text { Digital span } \\
\text { test_backward }\end{array}$ & $32.33 \pm 10.01$ & $35.53 \pm 11.14$ & 0.135 & $30.65 \pm 6.73$ & $34.65 \pm 9.80$ & $0.002 *$ \\
\hline Verbal learning test & $25.30 \pm 6.89$ & $28.30 \pm 3.50$ & $0.035 *$ & $27.50 \pm 6.10$ & $33.09 \pm 10.35$ & $0.001 *$ \\
\hline $\begin{array}{l}\text { Verbal learning } \\
\text { test_delayed }\end{array}$ & $25.20 \pm 6.85$ & $28.80 \pm 4.95$ & $0.021 *$ & $28.00 \pm 7.23$ & $33.65 \pm 13.43$ & $0.002 *$ \\
\hline $\begin{array}{l}\text { Visual span } \\
\text { test_forward }\end{array}$ & $30.90 \pm 9.70$ & $34.30 \pm 9.96$ & $0.017^{*}$ & $28.87 \pm 8.87$ & $37.12 \pm 10.43$ & $0.000 *$ \\
\hline
\end{tabular}


Table 2. Cont.

\begin{tabular}{|c|c|c|c|c|c|c|}
\hline & \multicolumn{3}{|c|}{ TBI } & \multicolumn{3}{|c|}{ Stroke } \\
\hline & $\begin{array}{c}\text { Pre- } \\
\text { Rehabilitation }\end{array}$ & $\begin{array}{c}\text { Post- } \\
\text { Rehabilitation }\end{array}$ & $p$-Value ${ }^{\dagger}$ & $\begin{array}{c}\text { Pre- } \\
\text { Rehabilitation }\end{array}$ & $\begin{array}{c}\text { Post- } \\
\text { Rehabilitation }\end{array}$ & $p$-Value $\ddagger$ \\
\hline $\begin{array}{c}\text { Visual span } \\
\text { test_backward }\end{array}$ & $29.66 \pm 7.26$ & $34.40 \pm 10.33$ & $0.005 *$ & $28.65 \pm 8.58$ & $35.03 \pm 9.33$ & $0.000 *$ \\
\hline Visual learning test & $34.43 \pm 11.27$ & $43.13 \pm 9.05$ & $0.001 *$ & $36.34 \pm 14.70$ & $44.84 \pm 10.33$ & 0.001 * \\
\hline $\begin{array}{l}\text { Visual learning } \\
\text { test_delayed }\end{array}$ & $39.46 \pm 13.89$ & $43.23 \pm 13.79$ & 0.160 & $42.03 \pm 16.60$ & $48.75 \pm 10.74$ & 0.027 * \\
\hline Auditory CPT & $28.36 \pm 9.59$ & $30.03 \pm 17.26$ & 0.545 & $30.06 \pm 9.14$ & $33.78 \pm 11.23$ & 0.004 * \\
\hline Visual CPT & $33.23 \pm 17.14$ & $38.66 \pm 20.89$ & 0.152 & $37.31 \pm 17.91$ & $44.75 \pm 19.71$ & 0.013 * \\
\hline Trail making test $\mathrm{A}$ & $21.86 \pm 14.75$ & $27.76 \pm 12.68$ & 0.008 * & $21.37 \pm 15.18$ & $29.75 \pm 11.73$ & 0.001 * \\
\hline Trail making test $\mathrm{B}$ & $10.40 \pm 17.63$ & $17.36 \pm 20.43$ & 0.012 * & $13.59 \pm 16.10$ & $20.96 \pm 19.37$ & 0.001 * \\
\hline Word-color test & $27.93 \pm 11.81$ & $31.36 \pm 10.28$ & 0.103 & $29.03 \pm 7.62$ & $29.37 \pm 7.75$ & 0.835 \\
\hline Card sorting test & $12.50 \pm 21.94$ & $18.16 \pm 26.00$ & 0.055 & $14.53 \pm 19.50$ & $29.34 \pm 21.53$ & 0.000 * \\
\hline $\mathrm{IQ}$ & $38.43 \pm 14.80$ & $46.46 \pm 18.81$ & 0.008 * & $35.87 \pm 16.71$ & $46.56 \pm 15.14$ & 0.002 * \\
\hline MMSE & $17.70 \pm 6.00$ & $22.73 \pm 4.66$ & 0.000 * & $20.44 \pm 4.99$ & $24.06 \pm 4.13$ & 0.000 * \\
\hline MBI & $47.00 \pm 27.91$ & $65.90 \pm 26.84$ & 0.000 * & $42.13 \pm 25.71$ & $65.59 \pm 23.99$ & 0.000 * \\
\hline
\end{tabular}

Mean \pm Standard deviation; CPT, continuous performance test; MMSE, Mini-Mental State Examination; MBI, modified Barthel index; ${ }^{\dagger} p$ value, comparison between pre- and post-cognitive rehabilitation in the TBI group; ${ }^{\ddagger} p$-value, comparison between pre- and post-cognitive rehabilitation in the stroke group; * $p$-value $<0.05$.

\subsection{Comparison between TBI and Stroke Groups}

We also compared the difference in values at pre- and post-cognitive rehabilitation for cognitive recovery TBI and stroke groups. All contents except the digital span forward, visual learning, word-color test, and MMSE had greater mean values in the stroke group and statistically significant higher values in the visual span forward and card sorting test $(p<0.05)$ (Table 3$)$.

Table 3. Comparison between the TBI and stroke groups on difference values at pre- and postcognitive rehabilitation.

\begin{tabular}{cccc}
\hline & TBI & Stroke & $p$-Value ${ }^{\dagger}$ \\
\hline Digital span test_forward & $4.73 \pm 9.32$ & $4 \pm 9.49$ & 0.76 \\
Digital span test_backward & $3.2 \pm 11.39$ & $4 \pm 6.64$ & 0.735 \\
Verbal learning test & $3 \pm 7.43$ & $5.59 \pm 8.37$ & 0.203 \\
Verbal learning test_delayed & $3.6 \pm 8.05$ & $5.66 \pm 9.66$ & 0.368 \\
Visual span test_forward & $3.4 \pm 7.32$ & $8.25 \pm 8.71$ & 0.02 * $^{*}$ \\
Visual span test_backward & $4.73 \pm 8.43$ & $6.38 \pm 8.48$ & 0.448 \\
Visual learning test & $8.7 \pm 12.37$ & $8.5 \pm 12.78$ & 0.95 \\
Visual learning test_delayed & $3.77 \pm 14.30$ & $6.72 \pm 16.35$ & 0.454 \\
Auditory CPT & $1.67 \pm 14.88$ & $3.72 \pm 6.77$ & 0.483 \\
Visual CPT & $5.43 \pm 20.24$ & $7.44 \pm 16.01$ & 0.666 \\
Trail making test A & $5.9 \pm 11.44$ & $8.38 \pm 12.21$ & 0.414 \\
Trail making test B & $6.97 \pm 14.14$ & $7.38 \pm 10.80$ & 0.898 \\
Word-color test & $3.43 \pm 11.17$ & $0.34 \pm 9.26$ & 0.24 \\
Card sorting test & $5.47 \pm 15.50$ & $14.81 \pm 20.16$ & $0.049{ }^{*}$ \\
IQ & $8.03 \pm 15.55$ & $10.69 \pm 17.47$ & 0.531 \\
MMSE & $5.03 \pm 4.15$ & $3.63 \pm 2.42$ & 0.113 \\
MBI & $18.9 \pm 14.94$ & $23.47 \pm 16.53$ & 0.259
\end{tabular}

Mean \pm Standard deviation; CPT, continuous performance test; MMSE, Mini-Mental State Examination; MBI modified Barthel index; ${ }^{\dagger} p$-value, comparison between the TBI and stroke groups on difference in values at preand post-cognitive rehabilitation; ${ }^{*} p$-value $<0.05$.

\section{Discussion}

In our study, we attempted to investigate the clinical effectiveness of computer-assisted cognitive rehabilitation in patients with acquired brain injury and the different treatment effects in patients between the TBI and stroke groups. First, comparing the contents of cog- 
nitive function evaluation at pre- and post-cognitive rehabilitation, statistically significant improvements were observed in most CNT items. Similar to the results of previous studies, computer-assisted cognitive rehabilitation has been effective in recovering cognitive function in patients with acquired brain injury $[16,29,31]$. Using the CNT assessment, different abilities of cognitive functions were assessed and each cognitive function subcategory was effective for recovery [30].

First, in the descriptive characteristic of Table 1, there was no item showing a significant difference between the TBI and stroke groups, so we thought that other variables except Comcog rehabilitation would not affect cognitive recovery in this study. In the TBI and stroke groups, significant improvement in cognitive functions was observed between pre- and post-rehabilitation [14,32,33]. In addition, more CNT contents (digit span backward, visual learning delayed recall, auditory CPT, visual CPT and card sorting test) have been statistically significantly improved in the stroke group. In the comparison between TBI and stroke groups on the difference values at pre- and post-cognitive rehabilitation, the stroke group showed a high difference value in most CNT items and statistically significant higher values were observed in visual span forward and the card sorting test. The reason that the cognitive function improved less in the TBI group than in the stroke group may be suggested by inflammation response after TBI. Indeed, the post-injury inflammation, which was mediated by microglia and macrophage, is influenced by existing neurodegenerative pathology [34,35]. Furthermore, several studies reported that there is a biological link between TBI and Alzheimer's disease (AD) [36-40]. First, population-based studies demonstrated that TBI during adulthood reduces the time to onset of AD [36]. Second, TBI animal model studies showed increased accumulation of amyloid precursor protein (APP), beta-amyloid $(A \beta)$, and pathological tau protein [37-39]. Third, accumulation of APP and extracellular deposition of $A \beta$ peptide in senile plaques has been identified in human brain tissue soon after severe TBI [40]. Since post-injury inflammation may be closely associated with neurodegenerative pathology, recovery of cognitive function after TBI may be less effective than that of cognitive rehabilitation after stroke.

Previous results have been obtained for differences in cognitive function impairment or recovery between TBI and stroke [24,41,42]. In our study, those who have strokes in the focal brain region tend to be better for cognitive function recovery after computer-assisted cognitive rehabilitation than TBI patients in CNT subcategories.

However, our study has a few limitations. First, patients were divided into TBI and stroke; however, the location or size of brain injury was not considered. Since which damaged cognitive domain in the brain or degree of brain injury damage is a factor influencing cognitive function recovery, additional consideration of these factors would have provided more assurance in the prognosis for cognitive function recovery in patients with TBI or stroke. Second, cognition is a function that includes complex elements of executive function, memory, visuospatial ability and/or language; therefore, the treatment and evaluation period in this study can be a bit short to see the pattern of cognitive function recovery. If further studies are conducted with more cognitive rehabilitation sessions and the number of cognitive function evaluations, the difference in cognitive function recovery between TBI and stroke groups could be prominent. Third, the amount of data is too small to develop an artificial intelligence (AI)-based tool that can extract the patterns we are looking for. If AI-based tools can be created based on big data, it is thought that it will be possible to more accurately and quickly predict cognitive recovery in patients with TBI and stroke.

\section{Conclusions}

Analyzing the contents of cognitive function evaluation at pre- and post-computerassisted cognitive rehabilitation in patients with TBI and stroke, most evaluation results showed improvement and the evaluation of patients with TBI and stroke also showed significant changes in cognitive functions in addition to more CNT contents with significant changes in patients with stroke. We also compared the difference in values at pre- and 
post-cognitive rehabilitation in the TBI and stroke groups. The stroke group showed a high difference value in most evaluation contents. Therefore, those who have strokes in the focal brain region tend to be better for cognitive function recovery after computer-assisted cognitive rehabilitation than patients with TBI, which can cause diffuse brain damage.

Author Contributions: Conceptualization, T.-D.J., E.P. and Y.-S.C.; methodology, T.-D.J.; software, J.-H.K., H.J. and J.-G.J.; validation, Y.-S.C., T.-W.N. and J.-H.K.; formal analysis, J.-H.K., J.-G.J. and H.J.; investigation, T.-W.N., J.-H.K., J.-G.J. and H.J.; resources, Y.-S.C., T.-W.N., J.-H.K., J.-G.J. and H.J.; data curation, Y.-S.C., T.-W.N., J.-H.K., J.-G.J. and H.J.; writing-original draft preparation, J.-G.J. and H.J.; writing-review and editing, T.-D.J., E.P.; visualization, H.J., J.-G.J. and C.-H.P.; supervision, T.-D.J. and E.P.; project administration, T.-D.J. All authors have read and agreed to the published version of the manuscript.

Funding: This research received no external funding.

Institutional Review Board Statement: The study was conducted according to the guidelines of the Declaration of Helsinki and approved by the institutional review board of the hospital (IRB No. 2019-05-008).

Informed Consent Statement: Informed consent was obtained from all subjects involved in the study.

Data Availability Statement: Available upon reasonable request.

Conflicts of Interest: The authors declare no conflict of interest.

\section{References}

1. Lucas, J.A.; Addeo, R. Traumatic Brain Injury and Postconcussion Syndrome. In Clinical Neuropsychology: A Pocket Handbook for Assessment, 2nd ed.; Snyder, P.J., Nussbaum, P.D., Robins, D.L., Eds.; American Psychological Association: Washington, DC, USA, 2006; pp. 351-380.

2. Miller, E.L.; Murray, L.; Richards, L.; Zorowitz, R.D.; Bakas, T.; Clark, P.; Billinger, S.A. Comprehensive overview of nursing and interdisciplinary rehabilitation care of the stroke patient: A scientific statement from the American Heart Association. Stroke 2010, 41, 2402-2448. [CrossRef] [PubMed]

3. Taylor, G.H.; Broomfield, N.M. Cognitive assessment and rehabilitation pathway for stroke (CARPS). Top. Stroke Rehabil. 2013, 20, 270-282. [CrossRef] [PubMed]

4. Tatemichi, T.K.; Desmond, D.W.; Stern, Y.; Paik, M.; Sano, M.; Bagiella, E. Cognitive impairment after stroke: Frequency, patterns, and relationship to functional abilities. J. Neurol. Neurosurg. Psychiatry 1994, 57, 202-207. [CrossRef] [PubMed]

5. Boake, C. History of Cognitive Rehabilitation Following Head Injury. In Cognitive Rehabilitation for Persons with Traumatic Brain Injury: A Functional Approach; Kreutzer, J.S., Wehman, P.H., Eds.; Paul H Brookes Publishing: Baltimore, MD, USA, $1991 ;$ pp. 3-12.

6. Gianutsos, R.; Zencius, A.H.; Lane, I.; Wesolowski, M.D. Cognitive rehabilitation: A neuropsychological speciality comes of age. Brain Inj. 1991, 5, 353-368. [CrossRef] [PubMed]

7. Cavanaugh, J.C.; Kramer, D.A.; Sinnott, J.D.; Camp, C.J.; Markley, R.P. On missing links and such: Interfaces between cognitive research and everyday problem-solving. Hum. Dev. 1985, 28, 146-168. [CrossRef]

8. Halligan, P.W.; Wade, D.T. The Effectiveness of Rehabilitation for Cognitive Deficits; Oxford University Press: Oxford, UK, 2005.

9. Sohlberg, M.M.; Mateer, C.A. Introduction to Cognitive Rehabilitation: Theory and Practice; Guilford Press: New York, NY, USA, 1989.

10. Wood, R.L.; Fussey, I. Cognitive Rehabilitation in Perspective; Routledge: Oxfordshire, UK, 2018; Volume 12.

11. Gontkovsky, S.T.; Gontkovsky, S.T.; McDonald, N.B.; Clark, P.G.; Ruwe, W.D. Current directions in computer-assisted cognitive rehabilitation. NeuroRehabilitation 2002, 17, 195-199. [CrossRef] [PubMed]

12. Lopresti, E.F.; Mihailidis, A.; Kirsch, N. Assistive technology for cognitive rehabilitation: State of the art. Neuropsychol. Rehabil. 2004, 14, 5-39. [CrossRef]

13. Bracy, O.L. Computer based cognitive rehabilitation. Cogn. Rehabil. 1983, 1, 7-8, 18.

14. Chen, S.H.A.; Thomas, J.D.; Glueckauf, R.L.; Bracy, O.L. The effectiveness of computer-assisted cognitive rehabilitation for persons with traumatic brain injury. Brain Inj. 1997, 11, 197-210. [PubMed]

15. Li, K.; Robertson, J.; Ramos, J.; Gella, S. Computer-based cognitive retraining for adults with chronic acquired brain injury: A pilot study. Occup. Ther. Health Care 2013, 27, 333-344. [CrossRef] [PubMed]

16. Sigmundsdottir, L.; Longley, W.A.; Tate, R.L. Computerised cognitive training in acquired brain injury: A systematic review of outcomes using the International Classification of Functioning (ICF). Neuropsychol. Rehabil. 2016, 26, 673-741. [CrossRef] [PubMed]

17. Yoo, C.; Yong, M.-H.; Chung, J.; Yang, Y. Effect of computerized cognitive rehabilitation program on cognitive function and activities of living in stroke patients. J. Phys. Ther. Sci. 2015, 27, 2487-2489. [CrossRef] [PubMed] 
18. Arciniegas, D.B.; Held, K.; Wagner, P. Cognitive impairment following traumatic brain injury. Curr. Treat. Options Neurol. 2002, 4, 43-57. [CrossRef] [PubMed]

19. Hanlon, J.A.D.; Zoran, M.; James, P.K.; Kelly, R.E. Effects of acute injury characteristics on neuropsychological status and vocational outcome following mild traumatic brain injury. Brain Inj. 1999, 13, 873-887.

20. Gennarelli, T.A.; Thibault, L.E.; Graham, D.I. Diffuse axonal injury: An important form of traumatic brain damage. Neuroscientist 1998, 4, 202-215. [CrossRef]

21. Rabinowitz, A.R.; Levin, H.S. Cognitive sequelae of traumatic brain injury. Psychiatr. Clin. N. Am. 2014, 37, 1. [CrossRef] [PubMed]

22. Barker-Collo, S.; Feigin, V. The impact of neuropsychological deficits on functional stroke outcomes. Neuropsychol. Rev. 2006, 16, 53-64. [CrossRef]

23. Yu, K.-H.; Cho, S.-J.; Oh, M.S.; Jung, S.; Lee, J.-H.; Shin, J.-H.; Koh, I.-S.; Cha, J.-K.; Park, J.-M.; Bae, H.-J.; et al. Cognitive impairment evaluated with Vascular Cognitive Impairment Harmonization Standards in a multicenter prospective stroke cohort in Korea. Stroke 2013, 44, 786-788. [CrossRef] [PubMed]

24. Zhang, H.; Zhang, X.N.; Zhang, H.L.; Huang, L.; Chi, Q.Q.; Zhang, X.; Yun, X.P. Differences in cognitive profiles between traumatic brain injury and stroke: A comparison of the Montreal Cognitive Assessment and Mini-Mental State Examination. Chin. J. Traumatol. 2016, 19, 271-274. [CrossRef] [PubMed]

25. Michel, J.; Mateer, C. Attention rehabilitation following stroke and traumatic brain injury. Eur. Med. 2006, $42,59-67$.

26. Sansonetti, D.; Hoffmann, T. Cognitive assessment across the continuum of care: The importance of occupational performancebased assessment for individuals post-stroke and traumatic brain injury. Aust. Occup. Ther. J. 2013, 60, 334-342. [CrossRef] [PubMed]

27. Nunnari, D.; Bramanti, P.; Marino, S. Cognitive reserve in stroke and traumatic brain injury patients. Neurol. Sci. 2014, 35, 1513-1518. [CrossRef] [PubMed]

28. Kim, Y.H.; Jang, E.H.; Lee, S.J.; Park, J.W.; Ko, M.H.; Park, S.H.; Shin, S.H.; Kim, Y.K. Development of computer-assisted memory rehabilitation programs for the treatment of memory dysfunction in patients with brain injury. J. Korean Acad. Rehabil. Med. 2003, 27, 667-674.

29. Kim, Y.H.; Ko, M.H.; Seo, J.H.; Park, S.H.; Kim, K.S.; Jang, E.H.; Park, S.W.; Park, J.H.; Cho, Y.J. Effect of computer-assisted cognitive rehabilitation program for attention training in brain injury. J. Korean Acad. Rehabil. Med. 2003, $27,830-839$.

30. Kim, Y.H.; Shin, S.H.; Park, S.H.; Ko, M.H. Cognitive assessment for patient with brain injury by computerized neuropsychological test. J. Korean Acad. Rehabil. Med. 2001, 25, 209-216.

31. Bogdanova, Y.; Yee, M.K.; Ho, V.T.; Cicerone, K.D. Computerized cognitive rehabilitation of attention and executive function in acquired brain injury: A systematic review. J. Head Trauma Rehabil. 2016, 31, 419. [CrossRef] [PubMed]

32. Fetta, J.; Starkweather, A.; Gill, J.M. Computer-based cognitive rehabilitation interventions for traumatic brain injury: A critical review of the literature. J. Neurosci. Nurs. 2017, 49, 235. [CrossRef]

33. Ye, M.; Zhao, B.; Liu, Z.; Weng, Y.; Zhou, L. Effectiveness of computer-based training on post-stroke cognitive rehabilitation: A systematic review and meta-analysis. Neuropsychol. Rehabil. 2020, 30, 1-17. [CrossRef]

34. Kokiko-Cochran, O.N.; Godbout, J.P. The inflammatory continuum of traumatic brain injury and Alzheimer's disease. Front. Immunol. 2018, 9, 672. [CrossRef] [PubMed]

35. Johnson, V.E.; Stewart, J.E.; Begbie, F.D.; Trojanowski, J.Q.; Smith, D.H.; Stewart, W. Inflammation and white matter degeneration persist for years after a single traumatic brain injury. Brain 2013, 136, 28-42. [CrossRef] [PubMed]

36. Nemetz, P.N.; Leibson, C.; Naessens, J.M.; Beard, M.; Kokmen, E.; Annegers, J.F.; Kurland, L.T. Traumatic brain injury and time to onset of Alzheimer's disease: A population-based study. Am. J. Epidemiol. 1999, 149, 32-40. [CrossRef]

37. Webster, S.J.; Van Eldik, L.J.; Watterson, D.M.; Bachstetter, A.D. Closed head injury in an age-related Alzheimer mouse model leads to an altered neuroinflammatory response and persistent cognitive impairment. J. Neurosci. 2015, 35, 6554-6569. [CrossRef] [PubMed]

38. Washington, P.M.; Morffy, N.; Parsadanian, M.; Zapple, D.N.; Burns, M.P. Experimental traumatic brain injury induces rapid aggregation and oligomerization of amyloid-beta in an Alzheimer's disease mouse model. J. Neurotrauma 2014, 31, 125-134. [CrossRef]

39. Itoh, T.; Satou, T.; Nishida, S.; Tsubaki, M.; Hashimoto, S.; Ito, H. Expression of amyloid precursor protein after rat traumatic brain injury. Neurol. Res. 2009, 31, 103-109. [CrossRef]

40. Roberts, G.W.; Gentleman, S.M.; Lynch, A.; Murray, L.; Landon, M.; Graham, D.I. Beta amyloid protein deposition in the brain after severe head injury: Implications for the pathogenesis of Alzheimer's disease. J. Neurol. Neurosurg. Psychiatry 1994, 57, 419-425. [CrossRef] [PubMed]

41. Castor, N.; El Massioui, F. Traumatic brain injury and stroke: Does recovery differ? Brain Inj. 2018, 32, 1803-1810. [CrossRef] [PubMed]

42. Basso, A.; Scarpa, M.T. Traumatic aphasia in children and adults: A comparison of clinical features and evolution. Cortex 1990, 26, 501-514. [CrossRef] 